\title{
Sildenafil to improve respiratory rehabilitation outcomes in COPD: a controlled trial
}

\author{
Isabel Blanco ${ }^{1,2}$, Salud Santos ${ }^{3}$, Joaqím Gea², ${ }^{2}$, Rosa Güell ${ }^{5}$, Ferran Torres ${ }^{6}$, \\ Elena Gimeno-Santos ${ }^{1}$, Diego A. Rodriguez¹, Jordi Vilarón ${ }^{1,2,7}$, Begona Gómez \\ Josep Roca ${ }^{1,2}$ and Joan Albert Barberà ${ }^{1,2}$
}

Affiliations: ${ }^{1}$ Dept of Pulmonary Medicine, Hospital Clínic - Institut d'Investigacions Biomèdiques August Pi i Sunyer (IDIBAPS), University of Barcelona, Barcelona, ${ }^{2}$ Centro de Investigación Biomédica en Red de Enfermedades Respiratorias, Barcelona, ${ }^{3}$ Dept of Pulmonary Medicine, Hospital Universitari de BellvitgeInstitut d'Investigació Biomèdica de Bellvitge, Barcelona, ${ }^{4}$ Dept of Pulmonary Medicine, Hospital del Mar Fundació Institut Mar d'Investigacions Mèdiques (IMIM), Universitat Pompeu Fabra, Barcelona, ${ }^{5}$ Dept of Pulmonary Medicine, Hospital de la Santa Creu i Sant Pau, Barcelona, ${ }^{6}$ Biostatistics and Data Management Platform, IDIBAPS, Biostatistics Unit, School of Medicine, Universitat Autònoma de Barcelona, Barcelona, ${ }^{7}$ Facultat de Ciències de la Salut Blanquerna, Grup de Recerca en Fisioteràpia, Universitat Ramon Llull, Barcelona, ${ }^{8}$ Dept of Pharmacy, Hospital Clínic, Barcelona, Spain.

Correspondence: J.A. Barberà, Servei de Pneumologia, Hospital Clínic, Villarroel 170, 08036 Barcelona, Spain. E-mail: jbarberaQclinic.ub.es

ABSTRACT Pulmonary hypertension is a serious complication of chronic obstructive pulmonary disease (COPD) that currently has no established pharmacological treatment. This study aimed to assess whether concomitant treatment with sildenafil would enhance the results of pulmonary rehabilitation in patients with COPD and increased pulmonary arterial pressure (PAP).

In this double-blind, randomised controlled trial patients received $20 \mathrm{mg}$ sildenafil or placebo three times daily and underwent pulmonary rehabilitation for 3 months. The primary end-point was the gain in the cycle endurance time at a constant work-rate. Secondary end-points included performance in the incremental exercise test, 6-min walk distance and quality of life.

63 patients with severe COPD and moderately increased PAP were randomised. Cycle endurance time increased by 149 s (95\% CI 26-518 s) in the sildenafil group and by 169 s (95\% CI 0-768 s) in the placebo group (median change difference -7 s, $95 \%$ CI -540-244 s; $p=0.77$ ). Gains in the incremental exercise test, 6 -min walk distance and quality of life at the end of the study did not differ between groups. Measurements of arterial oxygenation and adverse events were similar in both groups.

In patients with severe COPD and moderately increased PAP, concomitant treatment with sildenafil does not improve the results of pulmonary rehabilitation in exercise tolerance.

@ERSpublications

Sildenafil did not improve respiratory rehabilitation outcomes in patients with severe COPD and moderately increased PAP http://ow.ly/lh7cb

For editorial comments see page 893 .

This article has supplementary material available from www.erj.ersjournals.com

Received: Nov 012012 | Accepted after revision: Jan 252013 | First published online: Feb 212013

Clinical trial: This study is registered at www.clinicaltrials.gov with identifier number NCT01055405.

Support statement: The study was supported by grants from the Fondo de Investigación Sanitaria, Instituto de Salud Carlos III (EC07/90049), Pulmotension (EU IP-018723) and Societat Catalana de Pneumologia. I. Blanco was the recipient of a Research Training Fellowship from the Sociedad Española de Neumología y Cirugía Torácica. Sildenafil and placebo tablets were donated by Pfizer Inc (Sandwich, UK).

Conflict of interest: Disclosures can be found alongside the online version of this manuscript at www.erj.ersjournals.com Copyright @ERS 2013 


\section{Introduction}

Chronic obstructive pulmonary disease (COPD) is a highly prevalent lung disease that constitutes a major cause of death worldwide [1]. Dyspnoea on exertion is the most common symptom reported by COPD patients and is a major cause of disability.

Pulmonary hypertension is a frequent complication of COPD, present in $>50 \%$ of patients with severe disease [2]. Although pulmonary hypertension in COPD is usually of moderate severity, its presence is associated with shorter survival, more frequent exacerbations and an increased use of health resources [3]. While airflow obstruction is the major factor limiting exercise tolerance in COPD, recent data suggest that the presence of pulmonary hypertension might also contribute to exercise impairment $[4,5]$, particularly in those with severe pulmonary hypertension [6]. There is currently no pharmacological treatment for pulmonary hypertension in COPD [7].

Sildenafil, a phosphodiesterase (PDE)-5 inhibitor, improves exercise capacity in patients with pulmonary arterial hypertension [8]. Inhibition of PDE-5 acts on the nitric oxide signalling pathway in pulmonary vessels. It delays the degradation of cyclic guanosine monophosphate, thereby enhancing the vasodilator activity of nitric oxide [9]. Since in COPD the synthesis of nitric oxide in pulmonary arteries is impaired [10], sildenafil could be beneficial for treating COPD-associated pulmonary hypertension.

Pulmonary rehabilitation is an established intervention for the management of COPD as it improves exercise tolerance, reduces resting and exertional dyspnoea [11] and ameliorates health-related quality of life [12]. Pulmonary rehabilitation also improves exercise capacity and health-related quality of life in patients with pulmonary arterial hypertension [13].

We hypothesised that treatment with sildenafil in patients with COPD and associated pulmonary hypertension might improve the outcomes of pulmonary rehabilitation in terms of exercise tolerance, because patients under sildenafil would increase cardiac output and muscle blood supply on exertion at a greater extent, allowing them to train at higher intensity. To test this hypothesis, we conducted a proof-ofconcept, randomised controlled trial to assess whether concomitant treatment with sildenafil in patients with COPD and increased pulmonary arterial pressure (PAP) would enhance the effects of pulmonary rehabilitation on exercise tolerance.

\section{Methods}

\section{Design and overview}

The study was a 3-month, randomised, double-blind, placebo-controlled trial of oral sildenafil (20 mg three times daily) combined with pulmonary rehabilitation. Patients meeting eligibility criteria underwent baseline assessments and were randomised to receive sildenafil or placebo, beginning 1 week before starting pulmonary rehabilitation. The pulmonary rehabilitation programme took place three times per week for 12 weeks. Assessments were repeated at the end of the study.

The study was approved by institutional review boards in all the participating centres and all the patients signed informed consent before enrolment.

The study was an investigator-initiated clinical trial funded by the Instituto de Salud Carlos III, Spanish Ministry of Science and Innovation (Madrid, Spain). Pfizer Inc. (Sandwich, UK) donated sildenafil and identical tablets containing placebo but took no part in the study design, the accrual or analyses of data, or the preparation of the manuscript.

The trial was registered at www.clinicaltrials.gov with identifier number NCT 01055405.

\section{Setting and participants}

The study was conducted in four university hospitals in Barcelona, Spain. All the evaluation explorations, at baseline and at study termination, were centralised in the Hospital Clinic of Barcelona, which acted as the coordinating centre.

Recruited patients were aged between 40 and 80 years, diagnosed with COPD, according to the Global Initiative for Chronic Obstructive Lung Disease guidelines [1], and increased PAP. Patients were screened using Doppler electrocardiography. PAP was considered abnormally increased when the maximum tricuspid regurgitation velocity was $>2.7 \mathrm{~m} \cdot \mathrm{s}^{-1}$, which is equivalent to systolic PAP $>34 \mathrm{mmHg}$ [14], calculated using Bernoulli's equation, assuming a right atrial systolic pressure of $5 \mathrm{mmHg}$ [15]. In patients who had previously been subjected to right heart catheterisation $(n=14)$, we considered a definite diagnosis of pulmonary hypertension when the mean PAP was $\geqslant 25 \mathrm{mmHg}$. Other potential causes of pulmonary hypertension, such as chronic thromboembolic pulmonary hypertension or left heart disease, were 
excluded. A previous history of ischaemic or mitral or aortic valve diseases were exclusion criteria. In addition, electrocardiographic parameters to screen for left heart disease, such as ejection fraction, left atrium diameter, septum diameter, left ventricular mass index and posterior wall thickness, were between normal ranges. At randomisation, patients were in a stable clinical condition free of exacerbation episodes for $\geqslant 4$ weeks. Patients were not allowed to use sildenafil or other PDE-5 inhibitors and were excluded if they had a history of ischaemic heart disease, were treated with nitrates or were unable to exercise on a cycloergometer.

\section{Procedures}

Patients meeting eligibility criteria were randomly assigned in a 1:1 ratio to receive sildenafil or matched placebo via a four-permuted-block design, with no stratification. The randomisation was performed by a pharmacologist not involved directly in the study.

Before the study, each patient was evaluated using lung function tests, an incremental cardiopulmonary exercise test and a constant work-rate exercise test, both conducted on a cycloergometer [16], a 6-min walk test [17] and two questionnaires on health-related quality of life. The constant work-rate exercise, performed at a load equivalent to $70 \%$ of the maximal load the patient could tolerate on the incremental exercise test, served to assess the cycle time that could be tolerated at this work-rate (endurance time). The 6-min walk test was repeated every month. Health-related quality-of-life questionnaires included the Spanish versions of a disease-specific health index, the St George's Respiratory Questionnaire (SGRQ) [18], and a generic health index, the Medical Outcomes Study 36-Item Short Form Health Survey (SF-36) [19]. All these assessments were performed in the coordinating centre.

The pulmonary rehabilitation programme took place three times per week for 12 weeks and was standardised in the participating centres. Pulmonary rehabilitation consisted of exercise training sessions with a cycloergometer, conducted by specialised respiratory physiotherapists, designed in accordance with the American Thoracic Society and European Respiratory Society statement on pulmonary rehabilitation [20]. Each session comprised a warm-up period, followed by $40 \mathrm{~min}$ of cycling with interval training that combined high work rates (70-100\% of maximal workload) with low work rates $(40-50 \%$ of the maximal workload) and finally, a cooling-down period. Moreover, the patients worked on their upper limb strength twice a week. Oxygen saturation and heart rate were continuously monitored during the rehabilitation sessions. Limb fatigue and dyspnoea were assessed using the Borg scale. Patients on long-term oxygen used it during exercise training sessions. No other ventilatory support was prescribed during the study.

At the end of the study the incremental exercise test, the constant work-rate exercise test, the 6-min walk test and the health-related quality-of-life questionnaires were repeated in the coordinating centre. The constant work-rate exercise test at study termination was performed at the same load as at baseline.

\section{Outcome measures}

The primary end-point was the gain in exercise tolerance, assessed as the change in cycle endurance time in the constant work-rate exercise test. Key secondary outcomes were additional assessments of changes in exercise performance, including the maximal tolerated workload and peak oxygen uptake in the incremental exercise test, the distance covered in the 6-min walk test and changes in the scores of the health-related quality-of-life questionnaires.

\section{Safety evaluations}

As sildenafil may worsen pulmonary gas exchange in COPD [21, 22], arterial blood gases were measured at baseline and at study termination while breathing room air, both at rest and at peak exercise. An additional measurement was performed 1 month after starting treatment in the patient's usual conditions. Oxygen saturation was measured at rest in each rehabilitation session and continuously monitored during the session, as well as during the 6-min walk tests.

We also recorded the number and severity of acute COPD exacerbation episodes, and interviewed patients specifically about common side-effects of sildenafil.

\section{Statistical analysis}

Based on the study by EMTNER et al. [23], we estimated that the study, with 30 patients per treatment arm, had an $80 \%$ power to detect an additional increase in cycle endurance time after rehabilitation of $180 \mathrm{~s}$ in the sildenafil group, with a two-sided $5 \% \alpha$-value and an assumed standard deviation of $240 \mathrm{~s}$, compared with the gain obtained in the placebo group.

Categorical variables are described as frequencies and percentages, continuous variables as median and interquartile range and as mean \pm SD only for baseline data. To compare categorical variables we used the Fisher's exact test, and for continuous and ordinal variables we used the Mann-Whitney non-parametric 


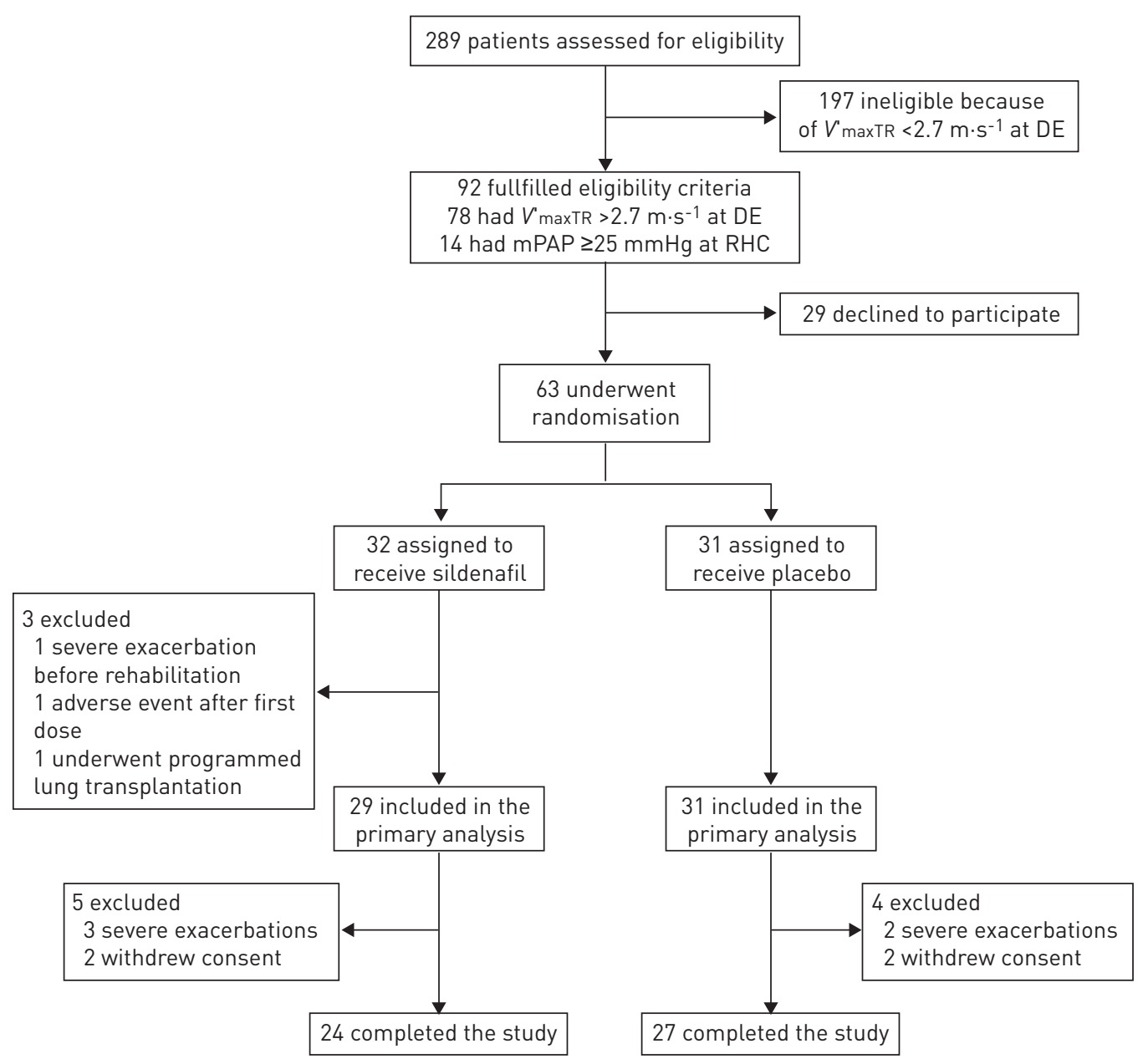

FIGURE 1 Screening, randomisation and follow-up of the study patients. A total of 289 patients were screened for pulmonary hypertension. 63 underwent randomisation. Of these patients, 60 made up the modified intention-to-treat population whose data were used in the primary effectiveness analysis. $V^{\prime}$ maxTR: maximum tricuspid regurgitation velocity; DE: Doppler electrocardiography; mPAP: mean pulmonary arterial pressure; RHC: right heart catheterisation.

test, with a subsequent estimate of the median difference and 95\% confidence interval based on the Hodges-Lehmann estimator [24].

The incidence rates and rate ratios associated with the two different types of variables were calculated using Poisson regression models.

The primary efficacy analysis was performed on the modified intention-to-treat population. We excluded one patient who presented an adverse event after the first treatment dose, one who suffered a severe exacerbation and could not start the rehabilitation and one who underwent lung transplant (fig. 1). Safety analysis was performed on the complete set of randomised patients.

Missing values of primary and key secondary end-points were imputed using a conservative value based on the 10th percentile of the overall response, except for the SGRQ, where the 90th percentile was used instead. The remaining variables were analysed using the approximation "available data only", without any imputation.

We also performed a post hoc analysis to evaluate the proportion of patients in each group who, after pulmonary rehabilitation, achieved the minimal important differences in cycle endurance time, established at $34 \%$ from baseline [25]; maximal workload in the incremental exercise test, established at $4 \mathrm{~W}$ [26]; 6-min walk distance, established at $26 \mathrm{~m} \mathrm{[26];} \mathrm{and} \mathrm{total} \mathrm{score} \mathrm{of} \mathrm{the} \mathrm{SGRQ,} \mathrm{established} \mathrm{at} 4$ points [27].

The level of statistical significance was set at the 5\% bilateral level. All the analyses were performed using the statistical package SAS version 9.2 software (SAS Institute, Cary, NC, USA). 
TABLE 1 Characteristics of the subjects participating in the study at baseline

Sildenafil Placebo

\section{Subjects}

Male

Age years

Body mass index $\mathrm{kg} \cdot \mathrm{m}^{-2}$

FVC $\%$ pred

FEV1 \% pred

FEV1/FVC

Total lung capacity $\%$ pred

Diffusing capacity for carbon monoxide \% pred

Maximum tricuspid regurgitation velocity $\mathrm{m} \cdot \mathrm{s}^{-1}$

Mean pulmonary artery pressure ${ }^{\top} \mathrm{mmHg}$

Brain natriuretic peptide $\mathrm{pg} \cdot \mathrm{mL}^{-1}$

Maximal exercise tolerance ${ }^{+} \%$ pred

Oxygen consumption at peak exercise ${ }^{+} \%$ pred

Cycle endurance time $\mathrm{s}^{5}$

6-min walk distance $\mathrm{m}$

Exercise dyspnoea score ${ }^{5}$ Borg scale

\section{9}

28 (97)

$66 \pm 8$

$27.0 \pm 5.1$

$67 \pm 16$

$33 \pm 12$

$0.37 \pm 0.09$

$114 \pm 17$

$40 \pm 15$

$3.06 \pm 0.32$

$32 \pm 6(n=9)$

$42 \pm 51$

$35 \pm 14$

$52 \pm 17$

$269 \pm 95$

$392 \pm 81$

$5.7 \pm 2.1$
Placebo

$$
\begin{gathered}
31 \\
26(84) \\
65 \pm 8 \\
26.6 \pm 4.6 \\
65 \pm 17 \\
31 \pm 10 \\
0.36 \pm 0.10 \\
116 \pm 23 \\
40 \pm 14 \\
3.06 \pm 0.26 \\
27 \pm 3(n=5) \\
62 \pm 73 \\
30 \pm 14 \\
47 \pm 14 \\
261 \pm 128 \\
379 \pm 100 \\
6.42 \pm 2.1
\end{gathered}
$$

Data are presented as $\mathrm{n}, \mathrm{n}(\%)$ or mean \pm SD. FVC: forced vital capacity; \% pred: \% predicted; FEV1: forced expiratory volume in $1 \mathrm{s.}{ }^{\#}$ : estimated by Doppler electrocardiography; ${ }^{\uparrow}$ : measured by right heart catheterisation; ${ }^{+}$: in the incremental cardiopulmonary exercise test; ${ }^{\S}$ : in the constant work-rate exercise test.

\section{Results}

\section{Study participants}

The screening, randomisation and follow-up of patients are shown in figure 1 . The patients were recruited from August 2008 to November 2010. 60 patients were valid for the efficacy analysis. 29 of them received sildenafil and 31 placebo. Characteristics of the participants at enrolment are summarised in table 1. Patients suffered from severe or very severe COPD with moderate-to-severe hypoxaemia. From the haemodynamic standpoint, patients selected by electrocardiography had a mean \pm SD maximum tricuspid regurgitation velocity of $3.06 \pm 0.28 \mathrm{~m} \cdot \mathrm{s}^{-1}\left(95 \%\right.$ CI $\left.2.98-3.14 \mathrm{~m} \cdot \mathrm{s}^{-1}\right)$, which is equivalent to an estimated systolic PAP of $42 \pm 10 \mathrm{mmHg}$. In patients who underwent right heart catheterisation, the mean PAP was $31 \pm 5 \mathrm{mmHg}$ and the cardiac index $2.74 \pm 0.47 \mathrm{~L} \cdot \mathrm{min}^{-1} \cdot \mathrm{m}^{-2}$. The exercise tests revealed moderate-to-severe impairment of exercise tolerance.

\section{Outcome measures}

At the end of the study, after 12 weeks of treatment combined with pulmonary rehabilitation, the cycle endurance time in the constant work-rate exercise test increased to a similar extent in patients receiving sildenafil and those receiving placebo, without differences between groups $(p=0.77)$ (table 2$)$. The proportion of patients improving cycle endurance time by the minimal important difference of $34 \%$ from baseline [25] was similar in both groups (table 3).

The effects of sildenafil on key secondary outcomes are summarised in table 2. In the incremental exercise test, the changes in maximal workload and peak oxygen uptake at the end of the study did not differ between the sildenafil and the placebo groups $(p=0.60$ and $p=0.07$, respectively). Furthermore, there were no differences at the end of study in the oxygen pulse and the anaerobic threshold (data not shown). The increase in the 6-min walk distance was also similar in both groups $(\mathrm{p}=0.94)$.

Differences in each individual component and in the total score of the SGRQ were similar in both groups ( $p=0.52$ for the total score) (table 2). In the SF-36 questionnaire, scores were indicative of poor health-related quality of life in all the measurements. The aggregate physical and mental scores are summarised in table 2 . At the end of the study, there were no between-group differences in the change observed in both scores.

The proportion of patients achieving the minimal important differences in maximal exercise workload [26], 6-min walk distance [26] and the total score of the SGRQ [27] did not differ between groups (table 3).

\section{Arterial oxygenation}

Study participants had moderate-to-severe hypoxaemia at rest and 18 of them were on long-term oxygen. There was no need to either prescribe supplementary oxygen because of worsening arterial oxygenation or remove any patient from the study due to critical oxygenation deterioration. 
TABLE 2 Effects of sildenafil in combination with pulmonary rehabilitation on efficacy outcomes

\begin{tabular}{|c|c|c|c|c|c|c|}
\hline & \multicolumn{2}{|c|}{ Baseline } & \multicolumn{2}{|c|}{ Change from baseline } & \multirow{2}{*}{$\begin{array}{l}\text { Sildenafil-placebo } \\
\text { change differences }\end{array}$} & \multirow[t]{2}{*}{ p-value } \\
\hline & Sildenafil & Placebo & Sildenafil & Placebo & & \\
\hline Cycle endurance time s & $268(205-331)$ & 221 (182-318) & 149 (26-518) & $169(0-768)$ & $-7(-540-244)$ & 0.768 \\
\hline Secondary outcomes & & & & & & \\
\hline $\begin{array}{l}\text { Maximal exercise } \\
\text { tolerance } \mathrm{W}\end{array}$ & $45(35-59)$ & $40(34-46)$ & $4(-1-8)$ & $2(0-5)$ & $1(-2-5)$ & 0.600 \\
\hline 6-min walk distance $\mathrm{m}$ & 397 (370-437) & $390(360-426)$ & $23(-12-40)$ & $21(-12-40)$ & $0(-33-29)$ & 0.935 \\
\hline SGRQ total score & $51.5(48.1-61.3)$ & $59.6(45.0-63.6)$ & $-1.6(-7.1-8.0)$ & $-0.7(-6.7-2.0)$ & $1.3(-3.5-6.9)$ & 0.526 \\
\hline $\begin{array}{l}\text { SF-36 aggregate physical } \\
\text { score }\end{array}$ & $33.0(30.5-39.4)$ & $31.3(24.2-35.9)$ & $-0.9(-6.5-3.0)$ & $0.6(-7.4-8.5)$ & $-1.7(-7.2-2.3)$ & 0.377 \\
\hline $\begin{array}{l}\text { SF-36 aggregate mental } \\
\text { score }\end{array}$ & $50.9(36.4-55.1)$ & $51.1(44.3-59.6)$ & $0.6(-7.5-3.0)$ & $-3.1(-13.7-3.5)$ & $1.6(-3.7-8.5)$ & 0.637 \\
\hline
\end{tabular}

Data are presented as median $(95 \% \mathrm{Cl})$, unless otherwise stated. $\mathrm{n}=29$ and $\mathrm{n}=31$ for sildenafil and placebo, respectively. Results are based on the imputed data using the 10th percentile to impute, except for St George's Respiratory Questionnaire (SGRQ), where the 90th percentile was used instead. SF-36: Medical Outcomes Study 36-item Short Form Health Survey.

No differences between groups were observed, during the study and at its end, in arterial oxygen tension or saturation, either at rest or during any of the exercise tests (table 4).

\section{Adverse events}

The clinical adverse effects reported in the overall set of randomised patients $(n=63)$ were similar in both groups (table 5). The most common adverse event was COPD exacerbation, which occurred in about onethird of patients, without differences between groups. The incidence ( $95 \% \mathrm{CI}$ ) of exacerbations per year was $2.11(1.16-3.85)$ in the sildenafil group and $1.79(1.07-2.98)$ in the placebo group, with a risk ratio (95\% $\mathrm{CI})$ of $1.18(0.54-2.60)(\mathrm{p}=0.68)$. The risk ratio for exacerbation episodes leading to study discontinuation was $2.11(0.41-10.99)(\mathrm{p}=0.38)$, and for those requiring hospitalisation it was $1.64(0.29-9.33)(\mathrm{p}=0.58)$.

\section{Discussion}

In this trial involving patients with COPD and increased PAP, concomitant treatment with sildenafil did not improve the effect of pulmonary rehabilitation on exercise tolerance.

Pulmonary hypertension is a serious complication of COPD [2], with no established treatment [1]. The availability of new treatments for pulmonary arterial hypertension [9] has prompted interest in their potential usefulness in conditions that may be associated with pulmonary hypertension, such as COPD [28]. Sildenafil has been shown to improve exercise tolerance in pulmonary arterial hypertension [8], but previous studies with sildenafil in COPD patients have yielded discrepant results. In two open-label studies conducted in a limited number of patients, sildenafil, used at doses higher than those currently approved for pulmonary arterial hypertension, improved exercise tolerance and pulmonary haemodynamics [29, 30]. In contrast, RIETEMA et al. [31] did not show differences in exercise tolerance and stroke volume in an uncontrolled study conducted in 14 COPD patients treated with conventional sildenafil doses. In a recent randomised controlled trial conducted in COPD patients with normal PAP, sildenafil also failed to improve exercise tolerance [22].

The severity of haemodynamic impairment in COPD-associated pulmonary hypertension is much less pronounced that in pulmonary arterial hypertension [32]. Therefore, it is not surprising that vasodilator treatment has little impact on exercise tolerance in COPD. However, it is currently unknown to what extent vasodilator treatment could have an impact on the results of a structured exercise training programme. We hypothesised that lowering PAP during exercise would be beneficial for patients with COPD undergoing pulmonary rehabilitation because it would allow them to train at a greater intensity, thereby improving the results of the rehabilitation programme. This was considered a clinically meaningful end-point because pulmonary rehabilitation provides well-established outcomes in COPD [1].

Our study is the first long-term, double-blind, placebo-controlled trial assessing the effects of targeted therapy in patients with COPD and increased PAP. In the present trial sildenafil failed to improve the 
TABLE 3 Patients exceeding the minimal important difference in study outcomes after pulmonary rehabilitation

\begin{tabular}{|c|c|c|c|c|}
\hline Subjects $n$ & & 29 & 31 & \\
\hline Maximal exercise workload & $+4 \mathrm{~W}[26]$ & $16(55)$ & $12(39)$ & 0.30 \\
\hline 6-min walk distance & $+26 \mathrm{~m} \mathrm{[26]}$ & $13(45)$ & $13(42)$ & 1.00 \\
\hline $\begin{array}{l}\text { Total score in St George's Respiratory } \\
\text { Questionnaire }\end{array}$ & -4 points [27] & $13(45)$ & $13(42)$ & 0.82 \\
\hline
\end{tabular}

Data are presented as $\mathrm{n}(\%)$, unless otherwise stated. $\mathrm{p}$-values derived from the Fisher exact test.

outcomes of pulmonary rehabilitation in terms of exercise tolerance. The increase in exercise capacity, assessed by the cycle endurance time at a constant work-rate as the primary end-point, was similar in the sildenafil and placebo groups. Furthermore, the proportion of patients achieving a clinically meaningful improvement in cycle endurance time did not differ between the groups. Similarly, the improvements obtained in patients treated with sildenafil in the incremental exercise test and in the 6-min walk test did not differ from those of the placebo group. Changes in health-related quality of life were also similar. Overall, these results show that in patients with COPD and increased PAP on electrocardiography, the addition of sildenafil does not enhance the results already obtained with pulmonary rehabilitation.

In patients with COPD and associated pulmonary hypertension, sildenafil decreases pulmonary vascular resistance both at rest and during exercise [21]. In the present series, this effect was not reflected in increased exercise capacity in patients who also underwent pulmonary rehabilitation. The lack of improvement in this group of patients with severe-to-very-severe airflow obstruction and mild-to-moderate pulmonary hypertension could be explained by the overwhelming effect of ventilatory impairment on exercise limitation, which would blunt the potential haemodynamic benefit obtained with sildenafil [6]. Nevertheless, patients in our series increased exercise capacity after rehabilitation and about half of them achieved clinically meaningful improvements, which is in line with previous studies [33]. The effect of pulmonary rehabilitation can be explained by the improvement in muscle function and reduction in ventilatory demand [34]. Conceivably, in our series these changes outweighed the eventual reduction in pulmonary vascular resistance produced by sildenafil. Our findings indicate that in patients with COPD and moderately increased PAP on electrocardiography, pulmonary rehabilitation is an adequate intervention to improve exercise capacity and the additional use of targeted therapy for pulmonary hypertension, namely sildenafil, does not provide further benefit.

Although sildenafil potentially entails the risk of worsening gas exchange in COPD [22] due to the inhibition of hypoxic pulmonary vasoconstriction [35], in the present study treatment with sildenafil was not associated with any significant deterioration in arterial oxygenation compared with placebo. It was not necessary to start long-term oxygen in any of the patients who did not previously receive it. Presumably, in patients who also underwent pulmonary rehabilitation, compensatory mechanisms may have counterbalanced the negative impact of hypoxic vasoconstriction inhibition [21, 35].

Sildenafil was well tolerated and adverse events were consistent with its known effects resulting from vasodilation. Most events were mild or moderate in severity and did not differ from those of the control group. The most frequent adverse events were exacerbation of COPD episodes, experienced by about onethird of the patients. These episodes led to treatment discontinuation in $10 \%$ of patients and required hospitalisation in $8 \%$, without any difference between the two groups.

The study has some limitations. First, pulmonary artery pressure was estimated by Doppler electrocardiography in the majority of cases. Therefore, a definite diagnosis of pulmonary hypertension could not be established in those cases. Only $22 \%$ of patients had pulmonary hypertension confirmed by right heart catheterisation. For the purposes of this proof-of-concept trial, the institutional review board considered that a noninvasive estimate of the PAP was more appropriate for screening patients before enrolment, taking into account that pulmonary hypertension is extremely frequent in COPD during exercise $[21,36]$ and that the objective of the study was to increase exercise capacity during exercise training. Although electrocardiography may yield some false positive estimations of pulmonary hypertension [7] and PAP increases with age [14], the characteristics of patients screened by electrocardiography, with a systolic PAP suggesting that pulmonary hypertension was possible or likely [7, 14], did not differ from those with pulmonary hypertension confirmed by right heart catheterisation, in terms of lung function, arterial 


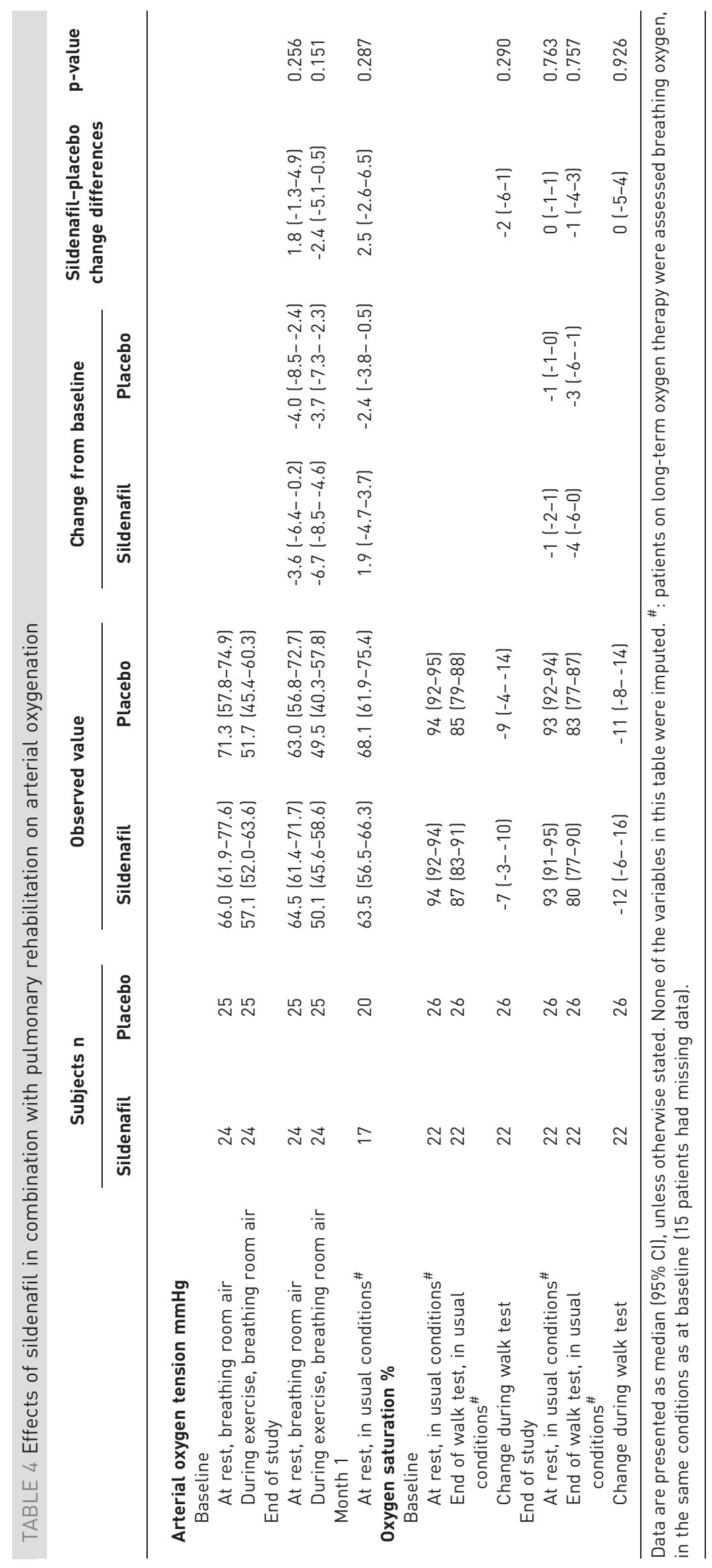


TABLE 5 Reported clinical adverse events and incidence of different types of exacerbations

\begin{tabular}{lccc} 
& Sildenafil & Placebo & p-value \\
\hline Subjects $n$ & 32 & 31 & \\
Subjects experiencing adverse events & $16(50.0)$ & $16(51.6)$ & 1.000 \\
Clinical worsening & & & \\
$\quad$ Death & $0(0)$ & $0(0)$ & 1.000 \\
Exacerbations leading to discontinuation & $4(12.5)$ & $2(6.5)$ & 0.592 \\
Exacerbations leading to hospitalisation & $3(9.7)$ & $2(6.5)$ & 0.915 \\
Adverse events & & & \\
COPD exacerbation & $10(31.3)$ & $11(35.5)$ & 0.794 \\
Headache & $2(6.3)$ & $1(3.2)$ & 1.000 \\
Angina pectoris & $1(3.1)$ & $0(0.0)$ & 1.000 \\
Arrhythmia & $0(0.0)$ & $1(3.2)$ & 0.493 \\
Dizziness & $1(3.1)$ & $0(0.0)$ & 1.000 \\
Somnolence & $1(3.1)$ & $0(0.0)$ & 1.000 \\
Gastritis & $1(3.1)$ & $0(0.0)$ & 1.000 \\
Peripheral oedema & $1(3.1)$ & $0(0.0)$ & 1.000 \\
Palpebral oedema & $1(3.1)$ & $0(0.0)$ & 1.000 \\
Blurred vision & $0(0.0)$ & $1(3.2)$ & 0.492 \\
Rhinorrhoea & $1(3.1)$ & $0(0.0)$ & 1.000 \\
Epistaxis & $0(0.0)$ & $1(3.2)$ & 0.494 \\
Diastolic hypertension & $0(0.0)$ & $1(3.2)$ & 0.491 \\
Hypotension & $0(0.0)$ & $1(3.2)$ & 0.491 \\
Psychiatric disorders & $0(0.0)$ & $1(3.2)$ & 0.491 \\
Depression & $0(0.0)$ & $1(3.2)$ & 0.491 \\
\hline
\end{tabular}

Data are presented as $\mathrm{n}(\%)$, unless otherwise stated. $\mathrm{p}$-values derived from the Fisher exact test. COPD: chronic obstructive pulmonary disease.

oxygenation and exercise tolerance (online supplementary tables S1 and S2). Furthermore, in terms of efficacy, there were no differences in the primary and secondary outcomes between catheterised patients that received sildenafil or placebo (online supplementary table S3). Secondly, left heart disease was excluded on the basis of clinical data and echocardiographic assessment. Nevertheless, we cannot completely exclude that subtle left ventricle diastolic dysfunction could have been overlooked in some cases, although it is unlikely that it differed between groups. Thirdly, study participants presented a mild-to-moderate increase in PAP associated with severe-to-very-severe airflow obstruction. In this situation, the ventilatory impairment may have an overwhelming effect on exercise tolerance. Therefore, our findings cannot be extrapolated to patients with severe pulmonary hypertension and moderate airflow obstruction (the so called out-of-proportion pulmonary hypertension in COPD) [7,37]. Nevertheless, a post hoc analysis restricted to patients with systolic PAP in the upper tertile $(>50 \mathrm{mmHg}$ ) revealed no differences between the sildenafil and control groups in the primary and key secondary outcomes. Fourth, we used a sildenafil dose of $20 \mathrm{mg}$ three times daily, which is the approved dose for the treatment of pulmonary arterial hypertension. Since sildenafil may exert greater haemodynamic effects at higher doses [8], we cannot rule out that higher sildenafil doses would have exerted a different effect on exercise tolerance. Finally, nearly all of the patients included in the study were male. Therefore, the current findings may not be applicable to females.

In summary, the present double-blind, randomised controlled trial, conducted in patients with COPD and increased PAP, failed to meet the primary end-point that sildenafil combined with pulmonary rehabilitation would provide further gain in exercise tolerance. As our patients had only moderately increased PAP, we cannot extrapolate the present results to patients with out-of-proportion pulmonary hypertension. Therefore, sildenafil should not be recommended to improve exercise capacity in patients with advanced COPD and mild-to-moderate pulmonary hypertension. In this condition, pulmonary rehabilitation is the preferred option for that purpose.

\section{Acknowledgements}

The authors would like to thank A. Barberan, F. Burgos, X. Alsina, C. Gistau and M. Simó (Dept of Pulmonary Medicine, Hospital Clínic, Barcelona, Spain) for their invaluable support and collaboration in the studies; A. Arbillaga (Hospital Clínic), G. Closa (Hospital Clínic), A. Balaña (Hospital del Mar, Barcelona), R. Planas (Hospital de Bellvitge, Barcelona) and D. Camara (Hospital de Bellvitge) for rehabilitation assessment and direction; J. Martinez-Llorens (Dept of Pulmonary Medicine, Hospital del Mar) and C. Puy (Dept of Pulmonary Medicine, Hospital de la Santa Creu i Sant Pau, Barcelona) for their contribution to patient recruitment and follow-up; M. Sitges (Dept of Cardiology, Hospital Clínic) and L. Molina (Dept of Cardiology, Hospital del Mar) for the electrocardiographic studies and L. Coronel (Hospital 
Clínic) for electrocardiographic review; and J.A. Arnaiz and J. Pich (Fundació Clínic per la Recerca Biomedica, Barcelona) for their collaboration in study oversight.

\section{References}

1 Vestbo J, Hurd SS, Agusti AG, et al. Global strategy for the diagnosis, management and prevention of chronic obstructive pulmonary disease: GOLD executive summary. Am J Respir Crit Care Med 2013; 187: 347-365.

2 Thabut G, Dauriat G, Stern JB, et al. Pulmonary hemodynamics in advanced COPD candidates for lung volume reduction surgery or lung transplantation. Chest 2005; 127: 1531-1536.

3 Kessler R, Faller M, Fourgaut G, et al. Predictive factors of hospitalization for acute exacerbation in a series of 64 patients with chronic obstructive pulmonary disease. Am J Respir Crit Care Med 1999; 159: 158-164.

4 Cuttica MJ, Kalhan R, Shlobin OA, et al. Categorization and impact of pulmonary hypertension in patients with advanced COPD. Respir Med 2010; 104: 1877-1882.

5 Sims MW, Margolis DJ, Localio AR, et al. Impact of pulmonary artery pressure on exercise function in severe COPD. Chest 2009; 136: 412-419.

6 Boerrigter BG, Bogaard HJ, Trip P, et al. Ventilatory and cardiocirculatory exercise profiles in COPD: the role of pulmonary hypertension. Chest 2012; 142: 1166-1174.

7 Galiè N, Hoeper MM, Humbert M, et al. Guidelines for the diagnosis and treatment of pulmonary hypertension. Eur Respir J 2009; 34: 1219-1263.

8 Galiè N, Ghofrani HA, Torbicki A, et al. Sildenafil citrate therapy for pulmonary arterial hypertension. $N$ Engl J Med 2005; 353: 2148-2157.

9 Humbert M, Sitbon O, Simonneau G. Treatment of pulmonary arterial hypertension. N Engl J Med 2004; 351: $1425-1436$.

10 Barberà JA, Peinado VI, Santos S, et al. Reduced expression of endothelial nitric oxide synthase in pulmonary arteries of smokers. Am J Respir Crit Care Med 2001; 164: 709-713.

11 Ries AL, Bauldoff GS, Carlin BW, et al. Pulmonary rehabilitation: joint ACCP/AACVPR evidence-based clinical practice guidelines. Chest 2007; 131: Suppl. 5, 4S-42S.

12 Lacasse Y, Goldstein R, Lasserson TJ, et al. Pulmonary rehabilitation for chronic obstructive pulmonary disease. Cochrane Database Syst Rev 2006; 4: CD003793.

13 Mereles D, Ehlken N, Kreuscher S, et al. Exercise and respiratory training improve exercise capacity and quality of life in patients with severe chronic pulmonary hypertension. Circulation 2006; 114: 1482-1489.

14 McQuillan BM, Picard MH, Leavitt M, et al. Clinical correlates and reference intervals for pulmonary artery systolic pressure among echocardiographically normal subjects. Circulation 2001; 104: 2797-2802.

15 Rudski LG, Lai WW, Afilalo J, et al. Guidelines for the echocardiographic assessment of the right heart in adults: a report from the American Society of Echocardiography endorsed by the European Association of Echocardiography, a registered branch of the European Society of Cardiology, and the Canadian Society of Echocardiography. J Am Soc Echocardiogr 2010; 23: 685-713.

16 Palange P, Ward SA, Carlsen KH, et al. Recommendations on the use of exercise testing in clinical practice. Eur Respir J 2007; 29: 185-209.

17 ATS Committee on Proficiency Standards for Clinical Pulmonary Function Laboratories. ATS statement: guidelines for the six-minute walk test. Am J Respir Crit Care Med 2002; 166: 111-117.

18 Ferrer M, Alonso J, Prieto L, et al. Validity and reliability of the St George's Respiratory Questionnaire after adaptation to a different language and culture: the Spanish example. Eur Respir J 1996; 9: 1160-1166.

19 Alonso J, Prieto L, Ferrer M, et al. Testing the measurement properties of the Spanish version of the SF-36 Health Survey among male patients with chronic obstructive pulmonary disease. J Clin Epidemiol 1998; 51: 1087-1094.

20 Nici L, Donner C, Wouters E, et al. American Thoracic Society/European Respiratory Society statement on pulmonary rehabilitation. Am J Respir Crit Care Med 2006; 173: 1390-1413.

21 Blanco I, Gimeno E, Munoz PA, et al. hemodynamic and gas exchange effects of sildenafil in patients with chronic obstructive pulmonary disease and pulmonary hypertension. Am J Respir Crit Care Med 2010; 181: 270-278.

22 Lederer DJ, Bartels MN, Schluger NW, et al. Sildenafil for chronic obstructive pulmonary disease: a randomized crossover trial. COPD 2012; 9: 268-275.

23 Emtner M, Porszasz J, Burns M, et al. Benefits of supplemental oxygen in exercise training in nonhypoxemic chronic obstructive pulmonary disease patients. Am J Respir Crit Care Med 2003; 168: 1034-1042.

24 Hodges JL, Lehmann EL. Estimates of location based on rank tests. Ann Math Statist 1963; 34: 598-611.

25 Puente-Maestu L, Villar F, de Miguel J, et al. Clinical relevance of constant power exercise duration changes in COPD. Eur Respir J 2009; 34: 340-345.

26 Puhan MA, Chandra D, Mosenifar Z, et al. The minimal important difference of exercise tests in severe COPD. Eur Respir J 2011; 37: 784-790.

27 Schünemann HJ, Griffith L, Jaeschke R, et al. Evaluation of the minimal important difference for the feeling thermometer and the St. George's Respiratory Questionnaire in patients with chronic airflow obstruction. J Clin Epidemiol 2003; 56: 1170-1176.

28 Hoeper MM. Treating pulmonary hypertension in COPD: where do we start? Eur Respir J 2008; 32: 541-542.

29 Alp S, Skrygan M, Schmidt WE, et al. Sildenafil improves hemodynamic parameters in COPD - an investigation of six patients. Pulm Pharmacol Ther 2006; 19: 386-390.

30 Madden BP, Allenby M, Loke TK, et al. A potential role for sildenafil in the management of pulmonary hypertension in patients with parenchymal lung disease. Vascul Pharmacol 2006; 44: 372-376.

31 Rietema H, Holverda S, Bogaard HJ, et al. Sildenafil treatment in COPD does not affect stroke volume or exercise capacity. Eur Respir J 2008; 31: 759-764.

32 Barberà JA, Blanco I. Pulmonary hypertension in patients with chronic obstructive pulmonary disease: advances in pathophysiology and management. Drugs 2009; 69: 1153-1171.

33 Troosters T, Gosselink R, Decramer M. Short- and long-term effects of outpatient rehabilitation in patients with chronic obstructive pulmonary disease: a randomized trial. Am J Med 2000; 109: 207-212.

34 Casaburi R, ZuWallack R. Pulmonary rehabilitation for management of chronic obstructive pulmonary disease. N Engl J Med 2009; 360: 1329-1335. 
35 Zhao L, Mason NA, Morrell NW, et al. Sildenafil inhibits hypoxia-induced pulmonary hypertension. Circulation 2001; 104: 424-428.

36 Barberà JA, Roger $\mathrm{N}$, Roca $\mathrm{J}$, et al. Worsening of pulmonary gas exchange with nitric oxide inhalation in chronic obstructive pulmonary disease. Lancet 1996; 347: 436-440.

37 Chaouat A, Bugnet AS, Kadaoui N, et al. Severe pulmonary hypertension and chronic obstructive pulmonary disease. Am J Respir Crit Care Med 2005; 172: 189-194. 